\title{
A Brief Talk on the Aesthetic Ideology in Vernacular Architecture of Northern Shandong Province
}

\author{
Zhang Xuan \\ Shandong University of Art \& Design, Jinan 250014, China \\ yoshiko33@163.com
}

Keywords: The vernacular architecture of Shandong province; the Aesthetic Ideology; aesthetic value

\begin{abstract}
The vernacular architecture of Shandong province contains great literary value and aesthetic value. This article has systematically analyzed from the perspective of aesthetics, which is the types of construction, production methods, rural construction environment and any other aspects. There are many new enlightenment and guidance for the design and innovation of modern architecture, at the same time, it also has an important impact on the protection and development of old rural buildings. To enhance people's awareness of protecting old buildings in northern Shandong.
\end{abstract}

\section{Introduction}

The vernacular architecture reflects the whole picture of the material and spiritual aspects of rural China ${ }^{[1]}$. The architectural form bears the entire content of the political, cultural, and economic development of rural China. The form of buildings in the countryside is changeable and most intension, most of the rural areas maintain an original way of life: grazing on the mountains and drinking water. Therefore, an area of land and water has its own architectural form. For example, the Jiaodong region is surrounded by sea on three sides, and most of the residents live on fishing. The materials used to construct houses are naturally sea-choked houses related to the sea. The color is also dominated by pure cool colors, which is in harmony with the sea culture and has a very high research value. For another example: There is a clear difference between the stone culture and the soil culture in the northern area of Shandong (mainly Binzhou and Dongying) and the sea culture in the Jiaodong area. In the north of Shandong, due to the closeness of the Yellow River, the main survival data is agriculture, which is rich in crops such as wheat, cotton, corn and soybeans. In terms of culture, it is influenced by Qi culture and Lu culture. The decorative culture and style of the building is also based on the patriarchal ritual system and hierarchical concepts of the Chinese feudal society. The decorative materials are mainly solid clay bricks made from loess and loess. At present, the Fifth Plenary Session of the 16th CPC Central Committee must vigorously promote traditional culture. The historical mission of promoting the building of a new socialist countryside will not only benefit hundreds of millions of peasants, but will also have significant implications for the protection of traditional Chinese folk culture. China is a big country in agriculture. Among them, the agricultural industry in Shandong has a large proportion, and native buildings derived from agriculture can better reflect the cultural connotations of big agricultural countries. Shandong native architecture will naturally also be called the direct embodiment of agricultural culture. Therefore, the study of characteristic dwellings in coastal rural areas has universal guiding significance both at home and abroad. Studying the aesthetic ideas of local architecture in the northern part of Shandong Province and establishing the aesthetic system of rural architecture can effectively provide a new perspective on the construction of new countryside. The protection of traditional rural architecture has the meaning of era and direction.

\section{The Beauty of Inurbanity and Faint}

The northern part of Shandong Province is located in the Yellow River Delta area, vegetation 
types in broad-leaved forest, shrub and meadow vegetation, salt etc., Most of the building materials are made from local materials, mainly loess. The mixed grass is mixed with water to make grass mud and dried in a fire pit. There are about two or three fire pits in a village, where bricks can be fired and processed into a mud and mortar wall as an essential material for building a house. The construction process of the old house, including the use of materials can not be considered exquisite, the initial measurement because of the reasons for the underdevelopment of technology, but also about the amount of line, not accounting for a cent. The wood used to build the beams will not be as polished, smooth and neat as the machine. Instead, it will retain the original qualities of wood, adding a natural, simple beauty to the building. The roof is sloping so that the rainwater can be discharged into the ground. The top is covered with cement and covered with cement. A large amount of hay is covered. The hay is tied together with a solid hemp rope and covered with mud so as not to cause the wind and rain to fall. The ride on the roof, especially a kind of unarticulated, real essence of beauty. Although the floor of the room is made of yellow earthen mats, it is not necessary to say that the potholes are natural. After a long time, the hard places are raised and stepped on like a large pebble. The carpenter polishes a few pieces of furniture at the village entrance. It does not have to be a noble pear or rosewood. The lush old poplar trees growing in the village are processed by a carpenter's hand and coated with insect-proof paint to make a table and chair bench with a sturdy structure. The cost of the earth embryo house is low, and the production process is relatively simple compared to the production process of the brick house. Adult males who have not learned the knowledge of building a house can quickly build the house within a month or two. The house built in this way, without the slightest refinement, has inadvertently formed the rough beauty most consistent with the surrounding environment and nature.

The so-called beauty is often developed by the practice of life. In a house built under such difficult conditions, our ancestors did not know when the beauty was discovered between these rough ones, and soon they used this to increase the effect of this beauty. This is a reflection and protection of tradition. The texture of the walls and walls of old houses in northern part of Shandong Province is undoubtedly the resonance of people's hearts. Compared with the bright glass of modern architecture, the bright and dazzling tableware that is crushed is as if all things have lost their exquisite light appearance, and it is difficult to open the teeth, pulling out the dark, rough roots. The Westerners wiped out all the bright things and invented electric lights to wipe out all the haze in the room. However, in the general trend, the old house has chosen the direction that accords with its own temperament. The old houses in northern part of Shandong Provinc were covered with thatched grass and the doors and windows built with thick planks and wooden strips filled the room with darkness. Because there is no large use of bricks and cement, in order to prevent rainwater from escaping, there must be a long roof on the roof. This led to a slight bleak lighting in the old house. The Chinese people have always had a preference for things that are stagnant and bleak and that have accumulated a sense of the times. Once we see sparkling things or are exposed to bright light, we will feel uneasy. We hate that kind of light. The ideological culture or education that we Orientals accept from childhood is rigorous and we must be good at hiding and not leaking. We love the attachment of human dirt, soot, sand, wind and dust, and even love can evoke the color and luster of their association. Once we live in such buildings and artifacts, we will feel wonderfully calm and peaceful. For example: Chinese people often love to play jade, experienced jade players are cool and that through the history of sedimentary texture and color with deep, deep and quiet, warm and clean Yingjie. Moreover, once the staff has spent too much time playing, the gloss that appears in the atmosphere of the owner has become very popular. Of course, we also think that bright rooms will make people feel bright and open, and the actions in the room will be more convenient. However, the beauty of this deep feeling is that under the habit of exposure to strong light, we have a temporary escape from the spirit. Beauty does not exist in objects, but in the haze and light and darkness produced by things and things. Modern people decorate their homes and begin to pursue spiritual and spiritual changes with the changes of light and shadows ${ }^{[2]}$. They will deliberately dispose of the window textures, and then use Shochi paper to cover the strong light outside, so that the room will be more and more shrouded at all. Not dazzling soft light. The shaded 
sunlight will bring spiritual enjoyment to people, which is incomparable with the effects of all lights on the modern market.

\section{The "Lazy Han Culture" Infiltrated by "Inaction" Thought}

"Inaction" ${ }^{[3]}$ laziness is not to say that like a real lazy man, it is a slovenly act, but that the ancestors lived a life of ploughing and cultivating men. The desire to conquer material desires was negative, and the children and grandchildren wandered around the knees. Happy enough. In ancient times, the noble people in the mountains who abandoned the secular world are left alone in huts to meditate. About this kind of old house created another kind of comfortable world for the holy man. Orientals are spiritual and moral. This morality was infiltrated by the thought of "inaction" and became a kind of laziness. The escape from the worldly world is back to nature and self-sufficiency. In an age when technology and information are extremely lacking, farmland is an important lifeline for the survival and development of people in northern part of Shandong Province region. The local culture, customs and taboos are the accumulation of life for hundreds of thousands of years. The people living in the area depend on the farmland and eat on the heavens. They fight with heaven and earth every moment, and the people are active in their survival. However, there is also a negative emotional sustenance in one aspect. The New Year pictures are one of the ways in which every household has to put in the room the emotions with blessings, and it is also the main decoration of the old house. Gates should be posted on the door to represent evil spirits to avoid ghosts, to protect the safety of the family home, good luck and other significance. Directly above the kitchen stove is affixed with a large stove King, a small stove king's New Year paintings to pray for homestead stability, farmland harvest and other significance. This conforms to nature, and it is spiritual and non-practical to replace the idea of protest with "no-action" prayer. In this kind of comfortable environment, I never thought about change, never thought about progress, and was far away from the pressure of the city. This kind of atmosphere seems to be the most appropriate place for people to escape stress.

We have never given up on the pursuit of lazyness. Lubei's rural architecture reveals a sense of lightness and inaction. The planning and layout of the village is surrounded by farmland, farmland surrounds the village, and the village of northern part of Shandong Province is a perfect combination of privacy and sociality. Here is the essence of the architecture of the northern villages. The village planning in northern part of Shandong Province is basically the multiple adjoining of houses and the fields behind the houses. The neighborhood is only a few steps away from each other, and the building density is very high. In this quiet, bleak, lonely environment, only thoughts and emotions are active ${ }^{[4]}$. This lazy atmosphere is a source of inspiration for poets and a quiet place to express emotions.

\section{The Ultimate Beauty of Clearness and Dryness}

The northern part of Shandong Province village building ${ }^{[5]}$, also known as the earth embryo house, was named after its use of local loess and meadow as the main material. The construction process of the earth embryo house is simple. The materials are locally sourced and ecologically friendly. They are mainly distributed in Binzhou, Dongying and Liaocheng cities in the northwest of northern part of Shandong Province and Lu, especially in Binzhou. The meadow is the most common type of vegetation in the area. It is harvested on the meadow and dried. It is smashed with a guillotine blade, and it is put into the loess to form grass. The main function is to use it as a wall construction and roof, and it is bonded to the cement by thickening. The thick roof can be longlasting and resistant to decay, effectively blocking wind and rain. In addition, meadows have a good ventilation and heat preservation effect, so the earth embryo houses built with meadows can be called unique ecological houses in the world.

From the analysis of aesthetics, the landscape color of the old house in Lubei is unique and distinctive, which enables people to feel the impressive regional feeling. The basic colors of house materials are used. The factors such as bricks made of loess, grass mud walls, and wood used for roofs and beams have unique and distinctive color characteristics. The combination of the warm 
yellow and wood brown-black color of the meadow and grass mud wall produces a sense of lightness, weight, and simplicity. Many homes have built more than a meter high grass-mud walls and wooden fences on the outskirts, and the courtyard has planted one or two jujube trees, grape vines, pomegranate trees and other trees. Agricultural tools are basically made of iron and wood. After the autumn harvest season, the harvested corn, peppers and garlic are hung on the windowsill and in the courtyard. This combination of unique courtyard landscape colors and unadorned courtyard walls has become an iconic element of the old buildings in northern part of Shandong Province.

The beauty of the old house is not the beauty of compromise. Its beauty is extreme, extremely negative, and extreme silence. If no one matches it, it will stay there quietly. The beauty and vitality of the old house depend on people and lighting. The interaction among the three is positive, close and inseparable. The stronger the atmosphere of life, the more frequent the interaction between people and people and the environment will be perfectly integrated with the village, and its style will become more and more distinctive. May be due to the silence of the old house, people will be more lively during the New Year. The sound of firecrackers beat the drums. In the light yellow wall paste the red couplet, in the window paste red paper-cutting, every family's door is affixed with red lanterns, such a strong contrast of color, loudly reminded people outside the village of vitality and passion. After the excitement, they returned to calm, and the remnants of firecrackers on the ground showed that there had been a carnival. Wait until the busy season, each household dug ditch irrigation, the flow of water is like the village's blood flow slowly. People in the village wore cloth shoes and crouched their heads. Stepping on this piece of yellow land did not make a sound. Just like the old house, every minute of every minute produced a strong rhythmic effect in both extremes to show the presence.

\section{Conclusion}

The earth embryo house in northern part of Shandong Province has gradually become one of the most representative original ecological houses in the world. The raw materials used in all of its building houses are taken from nature and finally returned to nature. This is very commendable. This reflects the wisdom of the people of northern part of Shandong Province and shows the people's worship and respect for nature through hardworking hands. These old houses are the best buildings that blend in with the environment. Quietness is a poem it is silently written. When standing in the distance, overlooking the entire village, it is bright and bright. Everyone will marvel at its indifference and beauty. The extraordinary artistic forms and natural native natural materials in northern part of Shandong Province residential buildings themselves give people a chance to fully understand the local culture. Leaves infinite beauty and wonder

\section{Acknowledgements}

The author is very grateful to the College Student Research Fund of Shandong University of Art \& Design (A Brief Talk on the Aesthetic Ideology in Vernacular Architecture of Northern China).

\section{References}

[1] Xiang Yang. Regional Expressing Strategies of New Rural Architecture in Northern Shandong Province [J]. Construction Science and Technology, 2017, 23: 51-55.

[2] Xie Na. The artistry of the design of home soft decoration [J]. Academy, 2017, 149.

[3] Shi Xiaoqian, Lei Yang, Qi Suping. Taoist thought of "Inaction" and modern design [J]. China Market, 2017, 6: 301+303.

[4] Li Jianguo. The architecture art and technology of Wei's Manor in Shandong Huimin [D]. Qingdao: Qingdao university of technology, 2012.

[5] Liu Hui, Du Feng. Primary study on energy efficiency design to rural dwellings in North Shandong [J]. Journal of Hebei University of Engineering(Natural Science Edition), 2017, 4: 50-52. 